\title{
Obesity, A Risk Factor for Mortality in SARS CoV-2 Infection: A Narrative Systematic Review
}

\author{
Sekhar Reddy ${ }^{1}$ Mohd Ashraf Ganie ${ }^{1}$ Parvaiz A. Koul ${ }^{2}$ Tajali Sahar ${ }^{1}$ Shaista Showkat ${ }^{1}$ \\ ${ }^{1}$ Department of Endocrinology, Sher-i-Kashmir Institute of Medical \\ Sciences, Srinagar, Jammu and Kashmir, India \\ 2 Department of Internal Medicine, Sher-i-Kashmir Institute of Medical \\ Sciences, Srinagar, Jammu and Kashmir, India \\ Address for correspondence Mohd. Ashraf Ganie, MBBS, MD, DM, \\ Department of Endocrinology and Metabolism, Sher-i-Kashmir \\ Institute of Medical Sciences, Srinagar, Jammu and Kashmir 190011, \\ India (e-mail: ashraf.endo@gmail.com).
}

ANAMS (India) 2022;58:2-10.

\begin{abstract}
Keywords

- SARS CoV-2

- COVID-19

- obesity and mortality

SARS CoV-2 is a $\beta$-coronavirus responsible for the current COVID-19 pandemic. Although there is increase severity and mortality described in the elderly population and people with co-morbidities, all age groups are susceptible to COVID-19. Recent data showed that obesity has also emerged as a significant risk factor for COVID-19 mortality. As per the WHO, most of the world's population lives in countries where obesity is highly prevalent. In this context, we aimed to review various studies that showed obesity as an independent risk factor for mortality in SARS CoV-2 infection. We followed the PRISMA guidelines to search for two databases including PubMed and Google Scholar using the key terms "COVID-19, OBES* and MORTALITY," SARS CoV-2, OBES* and MORTALITY" "COVID-19, OBESITY, and MORTALITY," SARS Cov-2, OBESITY and MORTALITY," respectively, up to August 3, 2020. Twelve studies were finally included in this review after applying inclusion and exclusion criteria. All 12 studies included in the review consistently showed that obesity is a risk factor for mortality in patients with SARS CoV-2 infection. These studies have also shown evidence that obesity leads to increased hospitalization, ICU admission, increased need for mechanical ventilation, and poor prognosis among patients with SARS CoV- 2 infection. Obesity is an independent risk factor for mortality in patients infected with this novel coronavirus. Appropriate triage, monitoring, and vigilance are required while dealing with individuals with obesity with SARS CoV2 infection, especially in the young obese population. More epidemiological studies need to be done taking BMI also into consideration in COVID-19 patients to find the exact cause of increased severity and mortality and develop appropriate preventive and therapeutic strategies.
\end{abstract}

\section{Introduction}

COVID-19 (coronavirus disease-2019) is caused by the coronavirus SARS-CoV-2 (severe acute respiratory syndrome- coronavirus-2), which was initially identified in Wuhan city, China, in a cluster of patients who presented with pneumonia of unknown cause in December 2019. It was observed that some patients with pneumonia developed published online December 3, 2021
DOI https://doi.org/ 10.1055/s-0041-1736506. ISSN 0379-038X.

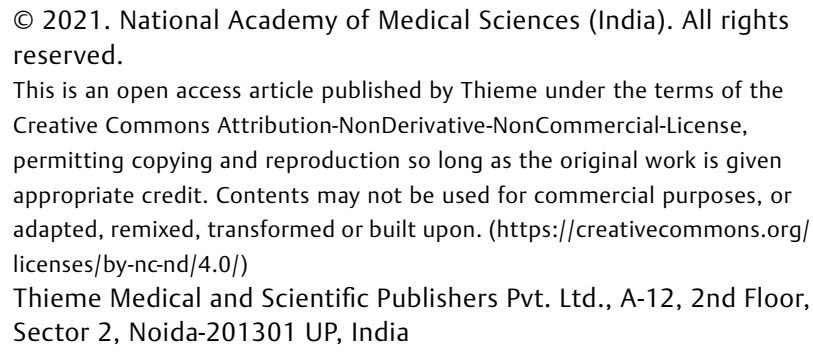

(C) 2021. National Academy of Medical Sciences (India). All rights reserved.

This is an open access article published by Thieme under the terms of the Creative Commons Attribution-NonDerivative-NonCommercial-License, permitting copying and reproduction so long as the original work is given appropriate credit. Contents may not be used for commercial purposes, or adapted, remixed, transformed or built upon. (https://creativecommons.org/ licenses/by-nc-nd/4.0/)

Thieme Medical and Scientific Publishers Pvt. Ltd., A-12, 2nd Floor, Sector 2, Noida-201301 UP, India 
acute respiratory distress syndrome (ARDS) requiring ventilation, and some of them worsened in a short period and died of multiple organ failure in China. ${ }^{1}$ Later, it has emerged as a rapidly spreading communicable disease affecting almost all countries globally and was declared as a pandemic by the WHO on March 11, 2020. As of November 10, 2020, there have been 50,676,072 confirmed COVID-19 cases, including $1,261,075$ deaths, reported to the WHO globally, and $86,36,011$ confirmed cases including $1,27,571$ deaths were reported from India. ${ }^{2}$

The disease severity ranges from asymptomatic and mild upper respiratory tract infection to pneumonia. Wu et al described the spectrum of disease as mild, severe, and critical. $^{3}$ Patients at high risk for SARS-CoV-2 infection have been characterized by pre-existing diseases such as hypertension, cardiovascular disease, diabetes, chronic respiratory disease, or cancer. ${ }^{4}$ Obesity has been rarely mentioned among the significant clinical risk factors for SARSCoV-2, reported in early clinical reports from China, ${ }^{5}$ Italy, ${ }^{6}$ and the United States. ${ }^{7}$ However, as the knowledge on this pandemic is evolving, further studies ${ }^{8,9}$ found that obesity is associated with severe COVID-19 outcomes as well.

Worldwide obesity has nearly tripled since 1975 and is now considered a pandemic. In 2016, more than 1.9 billion adults (39\%), 18 years and older, were overweight. Of these, over 650 million (13\%) had obesity. Over 340 million children and adolescents, aged 5 to 19 years were overweight or obese. ${ }^{10}$ Obesity has also been described as an independent predisposing factor to severe $\mathrm{H} 1 \mathrm{~N} 1$ pulmonary infection and mortality. ${ }^{11}$ As the COVID-19 pandemic is now rapidly spreading worldwide, there is a health care crisis in all the countries; therefore, there is a need to identify the high-risk group and provide more care to them to decrease the mortality rate. In this systematic review, we aimed to investigate whether obesity is an independent risk factor for mortality among patients with SARS CoV-2 infection.

\section{Methods}

This systematic review was conducted following the PRISMA (Preferred Reporting Items for Systematic Review and MetaAnalysis) guidelines. ${ }^{12}$ We searched PubMed using the key terms "COVID-19," "OBES*, "OBESITY" and "MORTALITY," "SARS CoV-2," and "COVID-19" up to August 3, 2020, as mentioned in -Table 1.

Table 1 Keys terms used for search in this review

\begin{tabular}{|l|l|c|}
\hline DATABASE & Key terms used & Hits \\
\hline PubMed & $\begin{array}{l}\text { COVID-19, OBES, } \\
\text { and mortality }\end{array}$ & 597 \\
\cline { 2 - 3 } & $\begin{array}{l}\text { SARS-CoV-2, OBES, } \\
\text { and mortality }\end{array}$ & 453 \\
\hline $\begin{array}{l}\text { Google Scholar } \\
\text { (search sorted with } \\
\text { relevance to date from } \\
\begin{array}{l}\text { December 2019 until } \\
\text { August 3, 2020) }\end{array}\end{array}$ & $\begin{array}{l}\text { COVID-19, obesity, } \\
\text { and mortality } \\
\text { SARS-CoV-2, obesity, } \\
\text { and mortality }\end{array}$ & 434 \\
& & \\
\hline
\end{tabular}

The inclusion criteria were studies that have taken BMI as a risk factor for mortality in adult patients with SARS-CoV-2 infection. The exclusion criteria are studies that have not taken BMI as a risk factor for mortality in SARS -CoV-2 infection and infections other than SARS-CoV-2 that are studied in the obese population. The aim of this study was to find if overweight/obesity is an independent risk factor for mortality in SARS CoV-2 infection. The final consensus among the authors regarding the studies to be included in this review was reached after developing a data extraction spreadsheet, matching a record of eligibility of the studies, describing study types, and applying inclusion criteria and exclusion criteria. Ethics committee approval was not required because it was a review study.

\section{Results}

Around 1,668 articles were identified in the literature search using key terms as mentioned in - Table 1, of which 66 articles were retrieved after title and abstract screening. Thirty-three articles were assessed in full text after removing duplicates. Finally, 12 studies were eligible to be included in this review after applying the inclusion and exclusion criteria as shown in the PRISMA flow chart in - Fig. 1.

of the 12 studies that were included, 10 were retrospective in nature, 1 was a prospective cohort study, and 1 was a cross-sectional study. In addition, 8 studies are from the United States of America, 2 from Italy, 1 from China, and 1 from Mexico. The subjects included in the studies were confirmed COVID-19 cases with a sample size ranging from 13 to 51,633 patients. In all studies, body mass index (BMI) between 25 and $29.99 \mathrm{~kg} / \mathrm{m}^{2}$ was considered as overweight, BMI $>30 \mathrm{~kg} / \mathrm{m}^{2}$ as obesity, except a study by Zhang et al in Wuhan, China, in which BMI 24 to $27.99 \mathrm{~kg} / \mathrm{m}^{2}$ was considered as overweight and BMI $>28 \mathrm{~kg} / \mathrm{m}^{2}$ was considered as obesity. The risk of mortality in obese patients in these studies is described as odds ratio (OR), adjusted hazard ratio (aHR), and relative risk (RR). The characteristics of the included studies, risk of mortality, and other outcomes related to overweight and obesity in patients with confirmed SARS CoV-2 infection are described in -Table 2. It is evident from these 12 studies that as the BMI increases from overweight $\left(25-30 \mathrm{~kg} / \mathrm{m}^{2}\right)$, obesity class $1\left(30-35 \mathrm{~kg} / \mathrm{m}^{2}\right), 2$ (35$40 \mathrm{~kg} / \mathrm{m} 2)$, and $3(\geq 40 \mathrm{~kg} / \mathrm{m} 2)$, there is an increase in the risk of mortality from SARS CoV-2 infection.

Giacomelli et al described that obese subjects had a threefold higher risk of death when compared with those with a BMI below $30 \mathrm{~kg} / \mathrm{m}^{2}$ in hospitalized patients during the first wave of the Italian epidemic. The proportion of obese patients in this study were $16.3 \%$ (38 out of 233 hospitalized patients), of whom 13 patients were in the non-survivor group. Apart from obesity, older age and advanced critical illness were factors independently associated with increased risk of mortality in this study. ${ }^{13}$ Palaiodimos et al assessed whether obesity is associated with worse outcomes independent of age, gender, and comorbidities. In this study, the patients were classified based on BMI as $\mathrm{BMI}<25 \mathrm{~kg} / \mathrm{m}^{2}$, BMI $25-34 \mathrm{~kg} / \mathrm{m}^{2}$, and $\mathrm{BMI} \geq 35 \mathrm{~kg} / \mathrm{m}^{2}$ as 
Obesity, COVID-19, and Mortality Reddy et al.

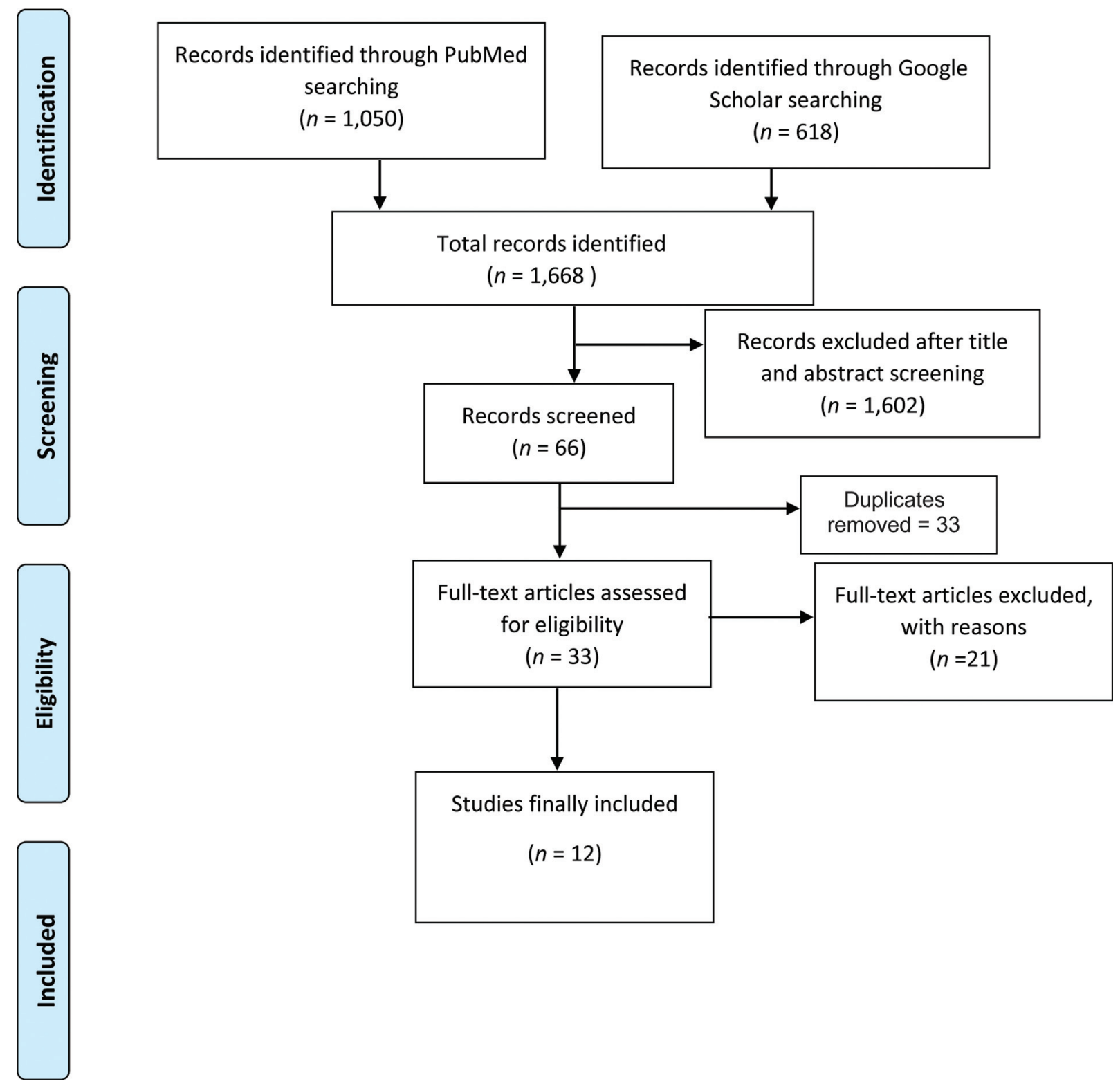

Fig. 1 PRISMA flow diagram.

per the most recent BMI assessment prior to or during the index admission, severe obesity is defined as BMI $>35$. It was observed that 16 (34.8\%) out of 46 patients in the severely obese group succumbed. Patients were also classified into four quartiles based on age: $\leq 50,51-64,65-73$, and $\geq 74$ years old. They demonstrated that severe obesity, increasing age, and male sex were independently associated with higher in-hospital mortality and in general worse in-hospital outcomes. $^{14}$

Zhang et al in a study in two hospitals from Wuhan included 13 young patients (14-45 years old) who died from COVID-19 and 40 matched controls and found that obesity is a high-risk factor predisposing to the death of young patients by aggravating inflammatory responses, cardiac damage, and increased coagulation activity. ${ }^{15}$ Steinberg et al conducted a two-center, retrospective cohort study that included 210 young adult patients (18-45 years old), of which 18 died during hospitalization (9\%), 36 (17\%) required mechanical ventilation, and 94 (45\%) were admitted. The limitation of this study is that co-morbid conditions such as diabetes and hypertension were not taken into account. ${ }^{16}$ Klang et al demonstrated obesity as an independent risk factor for mortality in patients younger than 50 years by retrospectively analyzing the data of COVID-19 patients; around $60(10.5 \%)$ out of 572 younger population and 1,076 (38\%) of 2,834 COVID-19 patients of age $>50$ years had died. In the younger population, BMI $>40 \mathrm{~kg} / \mathrm{m}^{2}$ was more strongly associated independently with mortality than the older population. ${ }^{17}$ Thus, from the above three studies it is clear that the obese young population is at high risk for mortality from SARS CoV-2 infection.

Rottoli et al in a multicentric retrospective cohort study from Italy aimed to find whether obesity is a risk factor for respiratory failure and death. Of 296 patients included in the study, 70 (23.6\%) were in the obese group with a BMI $\geq 30$ $\mathrm{kg} / \mathrm{m}^{2}$. A comparison between obese and non-obese groups 
Obesity, COVID-19, and Mortality Reddy et al. 5

\begin{tabular}{|c|c|c|c|c|c|c|c|c|}
\hline 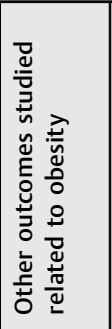 & & 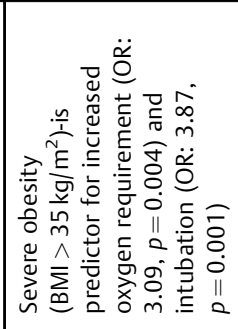 & 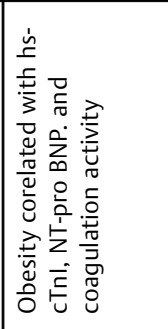 & 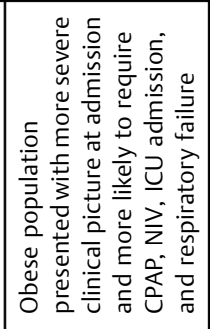 & 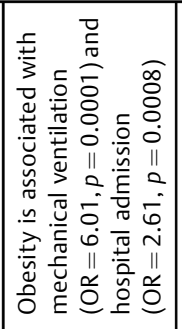 & 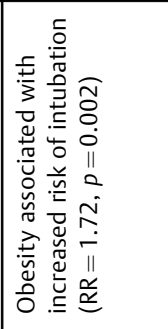 & 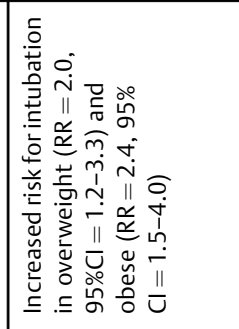 & 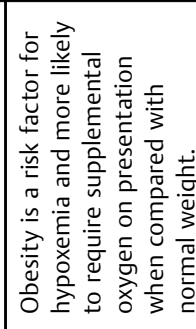 \\
\hline 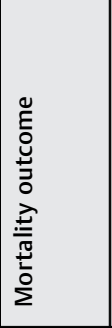 & 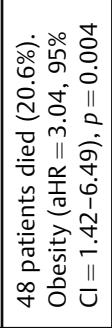 & 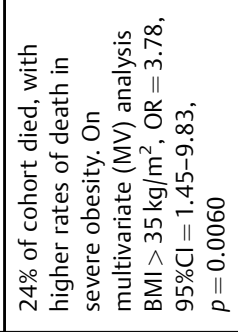 & 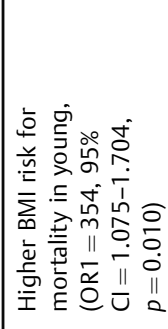 & 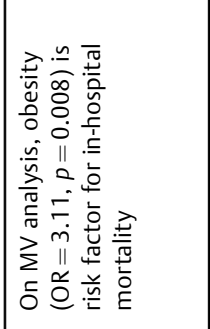 & 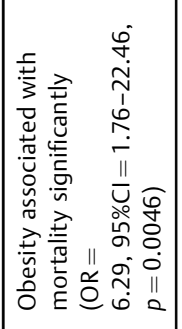 & 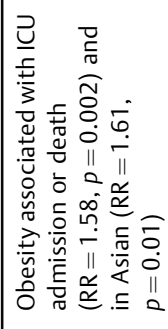 & 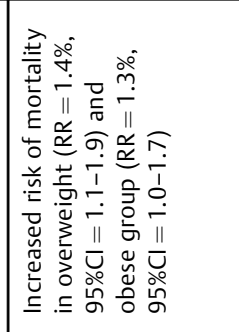 & 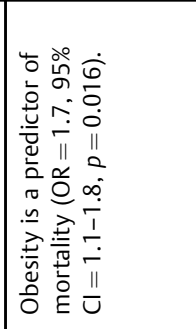 \\
\hline 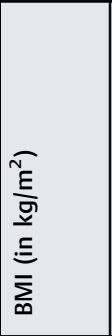 & $\stackrel{\circ}{\wedge}$ & 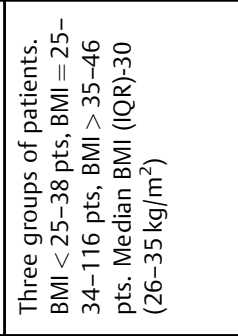 & 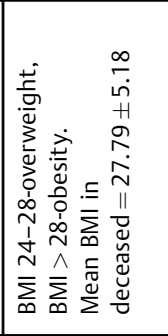 & 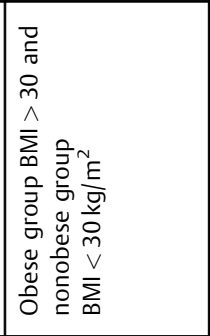 & 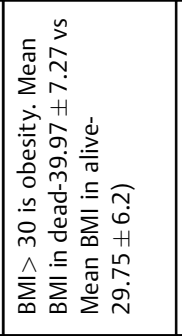 & 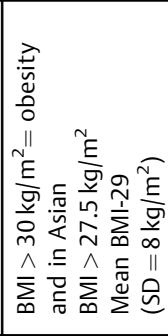 & 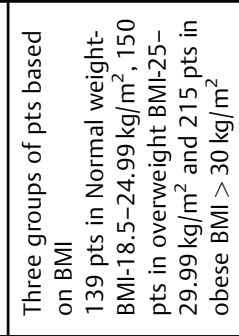 & 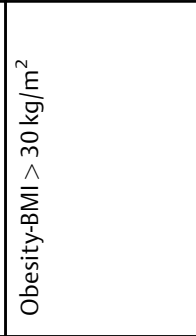 \\
\hline 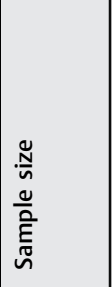 & 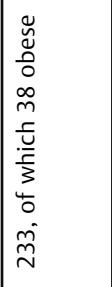 & 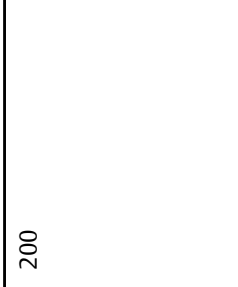 & 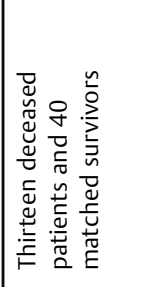 & 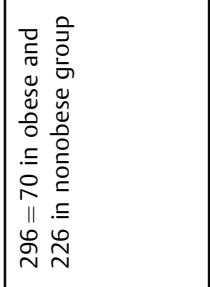 & $\stackrel{\circ}{\sim}$ & 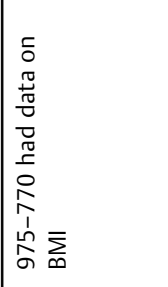 & 㝃 & 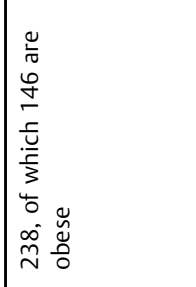 \\
\hline 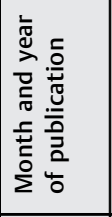 & 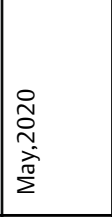 & 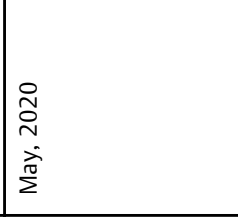 & 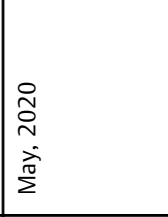 & 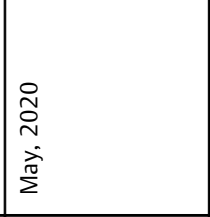 & 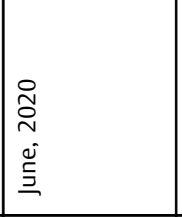 & 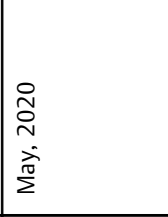 & $\begin{array}{l}\stackrel{0}{0} \\
\stackrel{0}{ } \\
\text { 立 }\end{array}$ & 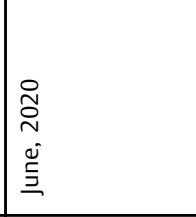 \\
\hline 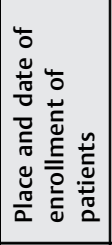 & 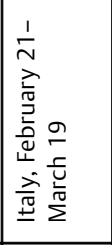 & 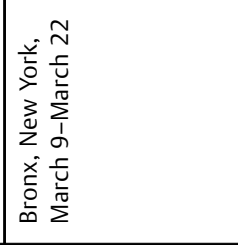 & 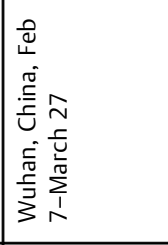 & 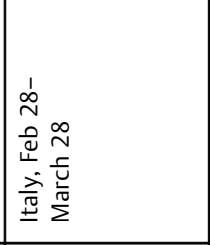 & 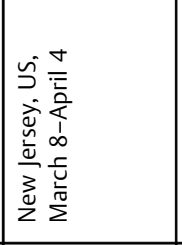 & 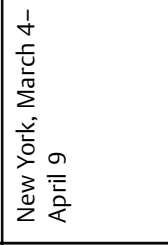 & 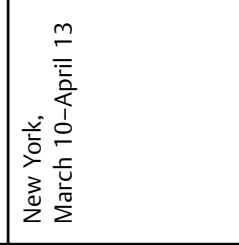 & 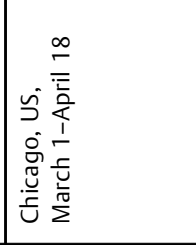 \\
\hline 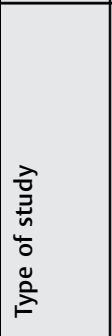 & 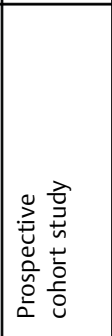 & 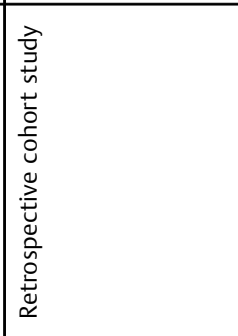 & 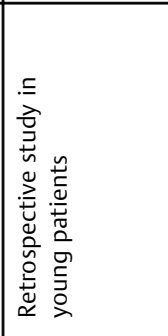 & 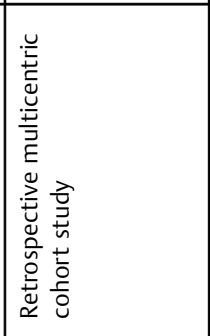 & 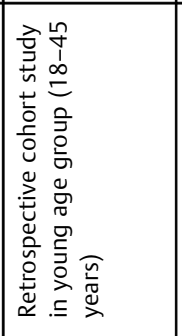 & 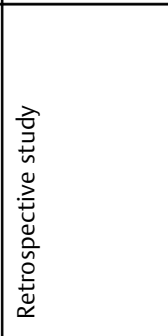 & 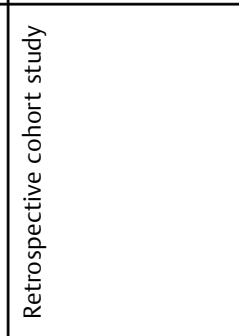 & 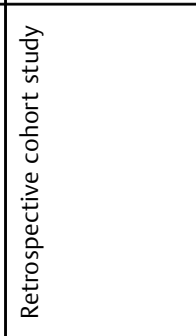 \\
\hline $\begin{array}{l}\text { 哀 } \\
\frac{\dot{z}}{z}\end{array}$ & 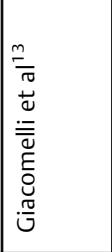 & 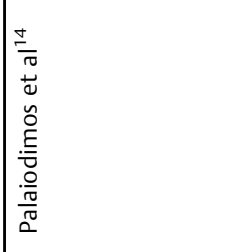 & 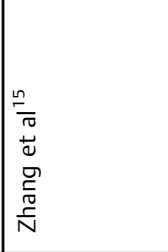 & $\begin{array}{l}\frac{\infty}{\bar{\pi}} \\
\frac{0}{0} \\
\overline{\overline{0}} \\
\overline{0} \\
\frac{0}{\alpha}\end{array}$ & 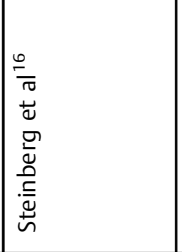 & 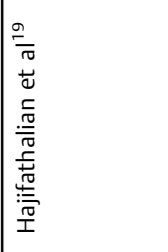 & 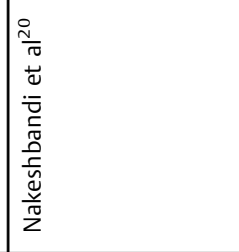 & 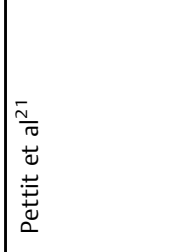 \\
\hline
\end{tabular}


6 Obesity, COVID-19, and Mortality Reddy et al.

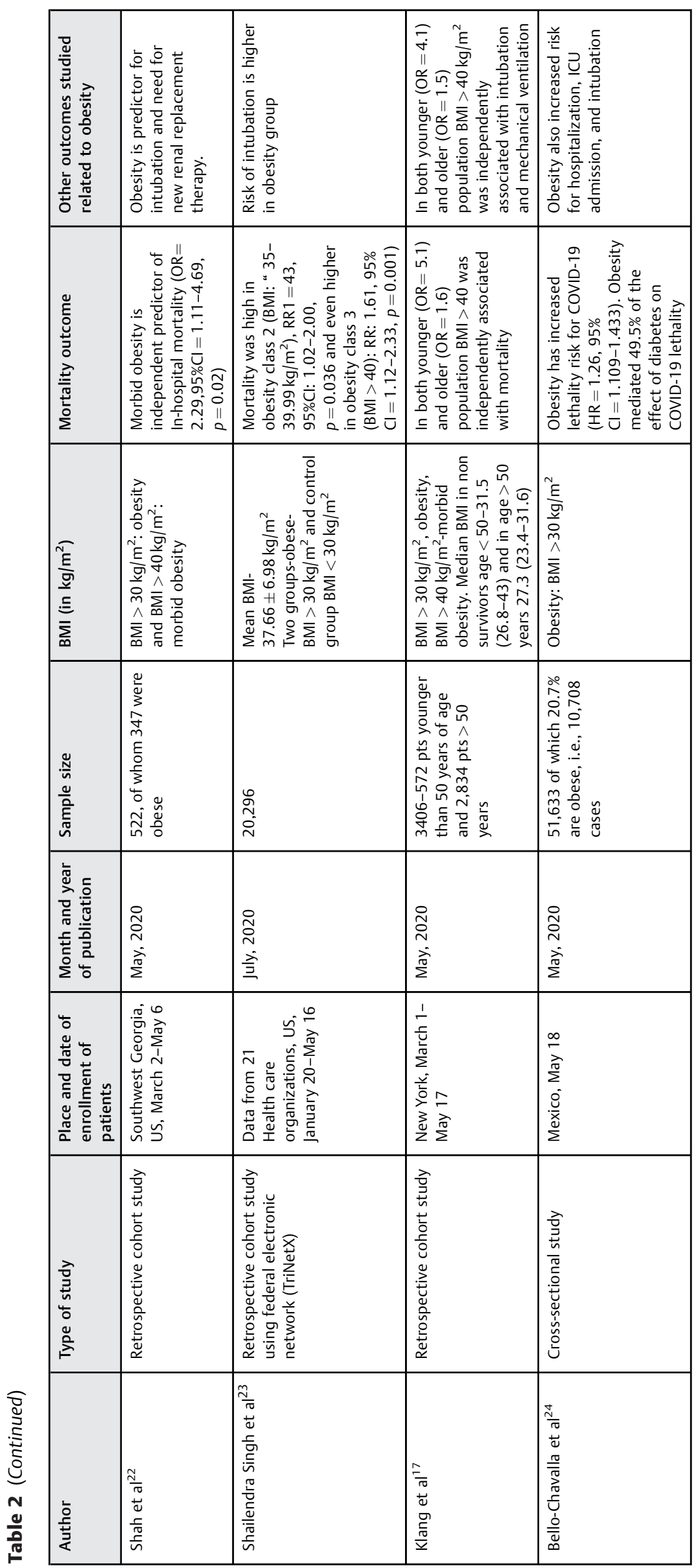

Annals of the National Academy of Medical Sciences (India) Vol. 58 No. 1/2022 @ 2021. National Academy of Medical Sciences (India). All rights reserved. 
regarding mortality in COVID-19 showed a significant difference between both groups ( $p<0.0005$ ), with the proportion of deaths in obese (38.6\%) more than non-obese $(17.7 \%)$. Obese patients were significantly older and reported a higher rate of hypertension, chronic obstructive pulmonary disease, type 2 diabetes, and moderate/severe renal disease. ${ }^{18}$ Hajifathalian et al described that obese patients were more likely to present with fever, cough, and shortness of breath and were also associated with a significantly high rate of ICU admission or death $(R R=1.58, p=0.002)$ even after adjusting for age, race, and troponin levels, ${ }^{19}$ whereas underweight were not associated with increased ICU admissions or death $(\mathrm{RR}=1.04, p=0.892)$. Older age, increased troponin I levels, and Asian race were other significant predictors of ICU admission or death in primary analysis with three categories of BMI (normal [including overweight] BMI $>18.5$ and $<30$ $\mathrm{kg} / \mathrm{m}^{2}$ [reference category], underweight BMI $<18.5 \mathrm{~kg} / \mathrm{m}^{2}$, and obese BMI $>30 \mathrm{~kg} / \mathrm{m}^{2}$ ) and for Asian race BMI categories were underweight BMI $<18.5 \mathrm{~kg} / \mathrm{m}^{2}$, normal (including overweight) $\mathrm{BMI}>18.5-27.5 \mathrm{~kg} / \mathrm{m}^{2}$, and obese $\mathrm{BMI} \geq 27.5 \mathrm{~kg} / \mathrm{m}^{2}$. The association between BMI and composite outcome of ICU admission or death is also evaluated using five categories of BMI (normal weight BMI $>18.5$ and $<25 \mathrm{~kg} / \mathrm{m}^{2}$ (reference category), underweight $\mathrm{BMI}<18.5 \mathrm{~kg} / \mathrm{m}^{2}$, overweight $\mathrm{BMI}>25 \mathrm{~kg} / \mathrm{m}^{2}$, and $\mathrm{BMI}<30 \mathrm{~kg} / \mathrm{m}^{2}$, obese BMI $>30 \mathrm{~kg} / \mathrm{m}^{2}$, and $\mathrm{BMI}<40 \mathrm{~kg} / \mathrm{m}^{2}$, and severely obese $\mathrm{BMI}>40 \mathrm{~kg} / \mathrm{m}^{2}$ ) in secondary analysis and it was found that obesity, defined as $>30 \mathrm{~kg} / \mathrm{m}^{2}$ and $\mathrm{BMI}<40 \mathrm{~kg} / \mathrm{m}^{2}$, was associated with a significantly higher rate of ICU admission or death compared with normal weight in multivariable analysis $(R R=1.57$, $p=0.012$ ) and severe obesity (i.e., BMI $>40 \mathrm{~kg} / \mathrm{m}^{2}$ ), showed a trend toward increasing risk, but did not reach statistical significance $(R R=1.75, p=0.065)$.

Nakeshbandi et al demonstrated in a retrospective cohort study in SUNY Downstate Health Sciences University, a COVID-only hospital in New York that there was a significantly increased risk of mortality in the overweight (BMI: 25-29.99 kg/m²) (RR: 1.4, 95\% CI: 1.1-1.9) and obese groups $(B M I \geq 30)$ (RR: $1.3,95 \%$ CI: 1.0-1.7) compared with those with normal BMI (18.5-24.99). Subgroup analyses were also performed based on sex and age. Obesity appears to significantly increase the risk of mortality in males (RR: $1.4,95 \% \mathrm{CI}$ : $1.0-2.0, p=0.03$ ) but not in females (RR: $1.2,95 \% \mathrm{Cl}: 0.77-$ $1.9, p=0.40) .{ }^{20}$ Age-stratified analyses demonstrated that among those 65 or older, being overweight significantly impacted mortality (RR: 1.5, 95\% CI: 1.2-2.0, $p=0.002$ ). Pettit et al did a retrospective cohort study to determine whether obesity is a predictor of mortality in hospitalized patients. A total of 238 patients were included, 218 patients (91.6\%) were African American, 113 (47.5\%) were male, and the mean age was 58.5 years. Of the included patients, 146 (61.3\%) were obese (BMI $\left.>30 \mathrm{~kg} / \mathrm{m}^{2}\right)$, with 63 (26.5\%), 29 (12.2\%), and 54 (22.7\%) with class 1,2 , and 3 obesity with BMI $30-35,35-40$, and $>40 \mathrm{~kg} / \mathrm{m}^{2}$, respectively. It was found that with every increase from one BMI category to the next, there was a $70 \%$ increased odds of mortality in the multivariable model. Obesity was identified as a predictor of mortality and also a risk factor for hypoxemia. Apart from obesity, male gender and old age were also found to be predictors of mortality in this study. ${ }^{21}$ Shah et al analyzed data using an electronic medical record of hospitalized COVID-19 patients at Phoebe Putney Health System in rural southwest Georgia and demonstrated that out of 522 hospitalized patients, 347 patients (66.5\%) were obese and 92 patients, died of whom 52 patients were obese (BMI $\geq 30 \mathrm{~kg} / \mathrm{m}^{2}$ ) and 23 patients (25.6\%) were morbidly obese (BMI $\geq 40 \mathrm{~kg} / \mathrm{m}^{2}$ ). Apart from morbid obesity, it was found that immunosuppression, hypertension, and age $>65$ years are independent predictors of increased mortality. 22

Shailendra Singh et al stratified COVID-19 cases into obese (BMI $\geq 30 \mathrm{~kg} / \mathrm{m}^{2}, 4,289$ members) and non-obese control group (BMI $<30 \mathrm{~kg} / \mathrm{m}^{2}, 3,814$ members). They found that patients in the obese group had significantly higher comorbidities, higher prevalence of respiratory symptoms, and higher inflammatory markers (CRP, ESR, and LDH), and higher proportions were hospitalized when compared with the control group. Subgroup analysis showed higher mortality in patients with obesity class 2 (BMI-35-39.99 $\mathrm{kg} / \mathrm{m}^{2}$ ) and class $3\left(\mathrm{BMI}>40 \mathrm{~kg} / \mathrm{m}^{2}\right) .{ }^{23}$ Bello-Chavolla et al described a mechanistic score relating obesity and diabetes to COVID-19 outcomes in Mexico and demonstrated that obesity is a COVID-19 specific risk factor for mortality, apart from it being a risk factor for ICU admission, tracheal intubation, and hospitalization. They also observed that obesity mediates $49.5 \%$ of the effect of diabetes on COVID-19 lethality and there was a fivefold increase in the mortality rate in obese patients with COVID-19. ${ }^{24}$

\section{Discussion}

The studies included in this review proved that obesity is an independent risk for mortality in patients with COVID-19 even after adjusting for age, gender, and co-morbidities, except in a study by Steinberg et al in which co-morbidities were not taken into account. Studies by Zhang et al, Steinberg et al, and Klang et al included in this review showed that obesity is a risk factor for mortality in the younger age group population (18-50 years). The papers included showed a variable mortality rate, which could be due to the differences in the sample size, race, BMI cutoffs, and selection bias. The articles included also demonstrated that overweight/obesity shows a correlation with the presentation with more severe symptoms, need for hospitalization, ICU admission, and mechanical ventilation in patients with this novel coronavirus infection. Thus, there is an increased need for medical care in the obese population, the prevalence of which is more in western countries when compared with Asian countries and could be one of the possible explanations for the health care crisis in countries such as the US and Italy.

Multiple explanations can be put forward for this apparent association between obesity and COVID-19 that include the following: Obesity can lead to altered respiratory physiology, obesity per se acts as a proinflammatory state and impairs immune surveillance, adipose tissue with an increase in the number of ACE2 receptors, and increased 
8 Obesity, COVID-19, and Mortality Reddy et al.

DPP4 activity, and associated cardiometabolic co-morbidities in obese patients. ${ }^{25}$

Obesity leads to direct mechanical changes due to fat deposition on the chest wall, abdomen, and upper airway, leading to limited chest wall expansion and obstructive sleep apnea, respectively. ${ }^{26}$ Pulmonary function abnormalities in obese patients include reduction in lung compliance, reduction in the expiratory reserve volume (ERV), functional residual capacity (FRC), and total lung capacity (TLC), and there is also a reduction in respiratory muscle strength, increased airway resistance, heterogeneity of ventilation distribution, increase in pulmonary diffusion, and hypercapnic respiratory failure in obesity. Superadded COVID-19 on already compromised lung function can increase the need for invasive mechanical ventilation as seen in the study by Simonnet et al. Excess fat could also lead to the possible presence of ectopic adipocytes with ACE2 receptors within the alveolar interstitial space that may suffer direct viral infection with SARS-CoV2 and, in turn, aggravate the inflammatory infiltrate, therefore contributing to the massive interstitial edema.

Excess adipose tissue in obese patients is associated with the production of various proinflammatory cytokines, including tumor necrosis factor- $\alpha$ (TNF- $\alpha$ ), interleukin-1- $\beta$ (IL$1 \beta$ ), and interleukin-6 (IL-6) and thus may lead to exaggerated cytokine storm and may play a role in SARS-CoV-2 driven hyperinflammation, leading to ARDS and multiorgan failure. There is increased susceptibility of obese individuals to oxidative damage due to depletion of enzymes that are active in antioxidant pathways, including superoxide dismutase (SOD), glutathione peroxidase, and catalase. Antioxidant pathways associated with vitamins $A, C$, and $E$ and $\beta$ carotene also seem to be depleted, thus compromising the host defense mechanism. ${ }^{27}$ Zinc is known to modulate antiviral and antibacterial immunity and regulate the inflammatory response. Zinc possesses anti-inflammatory activity by inhibiting the NF-KB signaling and modulation of regulatory $\mathrm{T}$ cell functions that may limit the cytokine storm during COVID-19 infection. Indirect evidence also indicates that $\mathrm{Zn}^{2+}$ may decrease the activity of angiotensin-converting enzyme 2 (ACE2), known to be the receptor for SARS$\mathrm{CoV}-2$. Obesity is mentioned among the risk groups associated with zinc deficiency along with aging, diabetes, and cardiovascular diseases. ${ }^{28,29}$

Excess adipose tissue can lead to increased visceral fat in areas such as atrioventricular and interventricular grooves. Adipokines released from epicardial fat can have a negative inotropic effect locally and increase systemic inflammation. In COVID-19 patients, there is a cytokine storm and dysregulated immune system, which can aggravate this epicardial fat-induced inflammation and lead to myocarditis and myocardial dysfunction in obese patients as hypothesized by Lei Zhao. ${ }^{30}$

Angiotensin-converting enzyme 2 (ACE2), a surface receptor for SARS-CoV, directly interacts with the spike glycoprotein (S protein). ${ }^{31}$ A study suggested that the affinity between ACE2 and the receptor-binding domain (RBD) of SARS-CoV-2 is 10 to 20 times higher than that with the RBD of SARS-CoV, indicating that ACE2 might also be the receptor for SARS-CoV-2. ${ }^{32}$ There is increased expression of ACE2 receptors with excess adipocytes seen in obese patients, thus facilitating the viral entry. ACE2 was reported to be widely expressed in various organ systems including the cardiovascular system, kidneys, lungs, and brain ${ }^{33}$ which could be an explanation why some COVID-19 patients died of multiple organ failure.

It is well known that MERS-CoV infection is mediated by the binding of its $S 1$ protein to the $\beta$-propeller domain of DPP4 for viral entry. ${ }^{34}$ Similarly, Vankadari and Wilce demonstrated a model that suggested a large binding interface between the SARS-CoV-2 S1 glycoprotein and DPP4, indicating a tight interaction and facilitating host cell binding and entry. ${ }^{35}$ DPP4 acts as a co-stimulator for T cell activation by binding to adenosine deaminase (ADA). It also enhances lymphocyte proliferation, independent of ADA binding. As adenosine is a potent suppressor of $\mathrm{T}$ cell proliferation, inducing its degradation through increased DPP4 activity can increase $\mathrm{T}$ cell proliferation. Obese subjects demonstrate increased levels of DPP4 expression in dendritic cell/macrophage cell populations from visceral adipose tissue, potentiating inflammation in obesity by interacting with $\mathrm{ADA},{ }^{36}$ so this immune dysregulation may also contribute to increased mortality during this novel coronavirus infection.

Obese individuals exhibit a persistent proinflammatory state that leads to insulin resistance, endothelial dysfunction, systemic arterial hypertension (SAH), and dyslipidemia. ${ }^{37}$ These factors culminate in type 2 diabetes mellitus (T2DM) 38 and promote atherogenesis, which in turn increases the risk of coronary heart disease, stroke, and heart failure; all these co-morbidities increase morbidity and mortality in patients with COVID-19 as shown in various studies across the globe. $^{39-42}$ The main limitation of this study is the qualitative analysis of the included study was not done; therefore, this is only a narrative systematic review.

\section{Conclusion}

Obesity has emerged as a significant risk factor for mortality apart from being a risk factor for increased hospitalization and severity in COVID-19 disease. Obesity leading to altered respiratory physiology, acting as a proinflammatory state, and association with cardiometabolic comorbidities can be a possible explanation for emerging as a risk factor for severe SARS-CoV-2 infection. So appropriate triage, monitoring, and vigilance are required while treating an obese patient with SARS-CoV2 infection, especially in young obese individuals and during this pandemic times as there is a health care crisis. As most of the countries in the world were in lockdown until recently with restriction of daily routines, which can increase the prevalence of obesity, with the relaxation of lockdown now preventive strategies such as moderate-intensity exercises, appropriate nutrition as per body weight, and measures to improve immunity should be taken as there is a long way to go until the availability of vaccine or development of herd immunity. More epidemiological 
studies need to be done taking BMI also into consideration in COVID-19 patients to find the cause of increased severity and mortality in this cohort and to develop appropriate preventive and therapeutic strategies.

\section{Conflict of Interest}

None declared.

\section{References}

1 Chen N, Zhou M, Dong X, et al. Epidemiological and clinical characteristics of 99 cases of 2019 novel coronavirus pneumonia in Wuhan, China: a descriptive study. Lancet 2020;395 (10223):507-513

2 Situation reports. Accessed April 16, 2020 at: https://www. who.int/emergencies/diseases/novel-coronavirus-2019/situation-reports/

$3 \mathrm{Wu}$ Z, McGoogan JM. Characteristics of and important lessons from the coronavirus disease 2019 (COVID-19) outbreak in China: summary of a report of 72314 cases from the Chinese center for disease control and prevention. JAMA 2020;323(13):1239-1242

4 Certain medical conditions and risk for severe COVID-19 illness | CDC. Accessed September 22, 2020 at: https://www.cdc.gov/ coronavirus/2019-ncov/need-extra-precautions/people-withmedical-conditions.html

5 Li Q, Guan X, Wu P, et al. Early transmission dynamics in Wuhan, China, of novel coronavirus-infected pneumonia. N Engl J Med 2020;382(13):1199-1207

6 Grasselli G, Zangrillo A, Zanella A, et al; COVID-19 Lombardy ICU Network. Baseline characteristics and outcomes of 1591 patients infected with SARS-CoV-2 admitted to ICUs of the Lombardy region, Italy. JAMA 2020;323(16):1574-1581

7 Bhatraju PK, Ghassemieh BJ, Nichols M, et al. Covid-19 in critically ill patients in the Seattle region-case series. N Engl J Med 2020; 382(21):2012-2022

8 Lighter J, Phillips M, Hochman S, et al. Obesity in patients younger than 60 years is a risk factor for COVID-19 hospital admission. Clin Infect Dis 2020;71(15):896-897

9 Simonnet A, Chetboun M, Poissy J, et al; LICORN and the Lille COVID-19 and Obesity study group. High prevalence of obesity in severe acute respiratory syndrome coronavirus-2 (SARS-CoV-2) requiring invasive mechanical ventilation. Obesity (Silver Spring) 2020;28(07):1195-1199

10 Obesity and overweight. Accessed September 26, 2020 at: https:// www.who.int/news-room/fact-sheets/detail/obesity-andoverweight

11 Van Kerkhove MD, Vandemaele KAH, Shinde V, et al; WHO Working Group for Risk Factors for Severe H1N1pdm Infection. Risk factors for severe outcomes following 2009 influenza A (H1N1) infection: a global pooled analysis. PLoS Med 2011;8 (07):e1001053

12 Moher D, Liberati A, Tetzlaff J, Altman DGPRISMA Group. Preferred reporting items for systematic reviews and meta-analyses: the PRISMA statement. PLoS Med 2009;6(07):e1000097

13 Giacomelli A, Ridolfo AL, Milazzo L, et al. 30-day mortality in patients hospitalized with COVID-19 during the first wave of the Italian epidemic: a prospective cohort study. Pharmacol Res 2020; 158:104931

14 Palaiodimos L, Kokkinidis DG, Li W, et al. Severe obesity, increasing age and male sex are independently associated with worse inhospital outcomes, and higher in-hospital mortality, in a cohort of patients with COVID-19 in the Bronx, New York. Metabolism 2020;108:154262

15 Zhang F, Xiong Y, Wei Y, et al. Obesity predisposes to the risk of higher mortality in young COVID-19 patients. J Med Virol 2020;92 (11):2536-2542
16 Steinberg E, Wright E, Kushner B. In young adults with COVID-19, obesity is associated with adverse outcomes. West J Emerg Med 2020;21(04):752-755

17 Klang E, Kassim G, Soffer S, Freeman R, Levin MA, Reich DL. Severe obesity as an independent risk factor for COVID-19 mortality in hospitalized patients younger than 50. Obesity (Silver Spring) 2020;28(09):1595-1599

18 Rottoli M, Bernante P, Belvedere A, et al. Obesity is one of the strongest risk factor for respiratory failure and death in COVID-19 patients: a retrospective multicentric cohort study. SSRN 2020. Doi: $10.2139 /$ ssrn.3578779

19 Hajifathalian K, Kumar S, Newberry C, et al. Obesity is associated with worse outcomes in COVID-19: analysis of early data from New York city. Obesity (Silver Spring) 2020;28(09): 1606-1612

20 Nakeshbandi M, Maini R, Daniel P, et al. The impact of obesity on COVID-19 complications: a retrospective cohort study. Int J Obes 2020;44(09):1832-1837

21 Pettit NN, MacKenzie EL, Ridgway JP, et al. Obesity is associated with increased risk for mortality among hospitalized patients with COVID-19. Obesity (Silver Spring) 2020;28(10):1806-1810

22 Shah P, Owens J, Franklin J, et al. Demographics, comorbidities and outcomes in hospitalized COVID-19 patients in rural southwest Georgia. Ann Med 2020;52(07):354-360

23 Singh S, Bilal M, Khan A, et al. Outcomes of COVID-19 in patients with obesity in United States: a large research network study. SSRN Electron J 2020. Doi: 10.2139/ssrn.3611983

24 Bello-Chavolla OY, Bahena-López JP, Antonio-Villa NE, et al. Predicting mortality due to SARS-CoV-2: a mechanistic score relating obesity and diabetes to COVID-19 outcomes in Mexico. J Clin Endocrinol Metab 2020;105(08):1-28

25 Yadav R, Aggarwal S, Singh A. SARS-CoV-2-host dynamics: increased risk of adverse outcomes of COVID-19 in obesity. Diabetes Metab Syndr 2020;14(05):1355-1360

26 Brazzale DJ, Pretto JJ, Schachter LM. Optimizing respiratory function assessments to elucidate the impact of obesity on respiratory health. Respirology 2015;20(05):715-721

27 Amirkhizi F, Siassi F, Minaie S, Djalali M, Rahimi A, Chamari M. Is obesity associated with increased plasma lipid peroxidation and oxidative stress in women? ARYA Atherosclerosis 2007;2(4[8]):189-192

28 Olechnowicz J, Tinkov A, Skalny A, Suliburska J. Zinc status is associated with inflammation, oxidative stress, lipid, and glucose metabolism. J Physiol Sci 2018;68(01):19-31

29 Haase $H$, Rink L. The immune system and the impact of zinc during aging. Immun Ageing 2009;6:9

30 Zhao L. Obesity accompanying COVID-19: the role of epicardial fat. Obesity (Silver Spring) 2020;28(08):1367

31 Kuba K, Imai Y, Rao S, et al. A crucial role of angiotensin converting enzyme 2 (ACE2) in SARS coronavirus-induced lung injury. Nat Med 2005;11(08):875-879

32 Wrapp D, Wang N, Corbett KS, et al. Cryo-EM structure of the 2019-nCoV spike in the prefusion conformation. Science 2020; 367(6483):1260-1263

33 Tipnis SR, Hooper NM, Hyde R, Karran E, Christie G, Turner AJ. A human homolog of angiotensin-converting enzyme. Cloning and functional expression as a captopril-insensitive carboxypeptidase. J Biol Chem 2000;275(43):33238-33243

34 Raj VS, Mou H, Smits SL, et al. Dipeptidyl peptidase 4 is a functional receptor for the emerging human coronavirus-EMC. Nature 2013;495(7440):251-254

35 Vankadari N, Wilce JA. Emerging WuHan (COVID-19) coronavirus: glycan shield and structure prediction of spike glycoprotein and its interaction with human CD26. Emerg Microbes Infect 2020;9 (01):601-604

36 Zhong J, Rao X, Deiuliis J, et al. A potential role for dendritic cell/macrophage-expressing DPP4 in obesity-induced visceral inflammation. Diabetes 2013;62(01):149-157 
10 Obesity, COVID-19, and Mortality Reddy et al.

37 Redinger RN. The pathophysiology of obesity and its clinical manifestations. Gastroenterol Hepatol (NY) 2007;3(11):856-863

38 Masmiquel L, Leiter LA, Vidal J, et al; LEADER investigators. LEADER 5: prevalence and cardiometabolic impact of obesity in cardiovascular high-risk patients with type 2 diabetes mellitus: baseline global data from the LEADER trial. Cardiovasc Diabetol 2016;15:29

39 Onder G, Rezza G, Brusaferro S. Case-fatality rate and characteristics of patients dying in relation to COVID-19 in Italy. JAMA 2020;323(18):1775-1776
40 Yang J, Zheng Y, Gou X, et al. Prevalence of comorbidities in the novel Wuhan coronavirus (COVID-19) infection: a systematic review and meta-analysis. Int J Infect Dis 2020;94:91-95

41 Yang X, Yu Y, Xu J, et al. Clinical course and outcomes of critically ill patients with SARS-CoV-2 pneumonia in Wuhan, China: a single-centered, retrospective, observational study. Lancet Respir Med 2020;8(05):475-481

42 Zhou F, Yu T, Du R, et al. Clinical course and risk factors for mortality of adult inpatients with COVID-19 in Wuhan, China: a retrospective cohort study. Lancet 2020;395(10229):1054-1062 